\title{
Modelling Undergraduate Student Engagement in China
}

\author{
Zhe Zhang \\ School of Humanities and Social Sciences, Harbin Institute of Technology (Shenzhen), China
}

\begin{abstract}
Against the background of the international audit culture and the associated higher education league tables, student engagement has become a pervasive indicator for measuring the education quality of institutions. This paper reports findings from a study investigating undergraduate student engagement at a Chinese university. Data were collected through questionnaire survey, individual interview and group interview methods. Survey findings will be the focus of attention of this paper. Five factors emerged from an exploratory factor analysis of the data: Effective Teaching Practices, Personal Development, Supportive Campus Environment, Collaborative, Reflective \& Integrative Learning, and Quality of Interactions (Student-Staff). Models about students' engagement and experiences (academic and non-academic) were developed on the basis of these factors and two background variables (School and Year), using a multi-model building strategy. The findings contribute to the dominant paradigm of student engagement by specifying the magnitude of significant indicators mediating different aspects of students' engagement and experiences, and will inform the future policies and practices of institutions.
\end{abstract}

Index Terms - student engagement, student experience, Chinese university, higher education

\section{INTRODUCTION}

In recent years, the international audit culture and the associated higher education league tables have led universities to become increasingly aware of research and teaching performance, and student outcomes and engagement as key indicators for measuring excellence. How to attract and retain students, satisfy their development needs and ensure that they become employment-ready when they graduate appears ever more crucial to all universities in the global market. Owing to this consumer orientation and the well-evidenced relations between students' engagement and positive learning outcomes (see below), student engagement has become a buzzword in the past fifteen years in higher education institutions and sectors.

Student engagement has been used in a pervasive way, which perhaps has led to the consequence that as a concept it is not problematised in the literature to the extent that it might warrant, and some researchers argue about whether the literature has been sufficiently critical (e.g., Trowler 2015 vs. Zepke 2014a \& Zepke 2014b). For example, it is not uncommon to see in the literature that "student engagement" is mixed up with one of its precursors "student involvement" (Astin 1984) and some researchers use the two terms interchangeably; but, as Wolf-Wendel, Ward and Kinzie (2009) explain, at least in North America, they are distinct constructs ${ }^{1}$. Although student engagement has almost become a ubiquitous term "interpreted and applied in a variety of ways across different higher education contexts and sectors" (Solomonides 2013, p. 45), as a construct firmly rooted in cultural and social norms, what it truly means to students in different cultures, and what influences students' engagement preferences, are still not well explored (Ross, Cen, and Shi 2014). As a result, China, which is remarkably different from western countries in terms of social, cultural and political contexts, and currently the largest source country of international students, has been brought into sharp focus. It thus seems worthwhile and necessary to explore perceptions of the more discerning and cost-conscious consumers in China. This paper reports survey findings from two courses (mathematics and Chinese language) at a Chinese university. It focuses on the latent factor structure of students' responses to a survey questionnaire and explores the magnitude of these factors in mediating students' engagement and experiences. It contributes to the dominant paradigm of student engagement by identifying varied combinations of key factors influencing different aspects of students' engagement and experiences.

In the remaining sections, we will firstly review key relevant literature, and then introduce the methodology of the empirical research underpinning this paper. Following this we will present the factoring and modelling results. The last section will discuss the implications of the results, summarise the findings and suggest topics for future research.

\section{STUdENT ENGAGEMENT}

\section{A. The Dominant Paradigm}

\footnotetext{
${ }^{1}$ According to Wolf-Wendel et al. (2009), "student engagement" represents two components: the first, time and efforts that students invest in learning and other activities, and the second, the institutional efforts to encourage students to participate in and benefit from such activities; while "student involvement" focuses on student efforts only.
} 
Research about student engagement originated in the US over 50 years ago. Earlier concepts such as Merwin's (1969) “time-on-task", Astin's (1984) "student involvement" and Pace's (1980, 1984) "quality of effort" have been important precursors of the construct of student engagement. With the annual administration of the National Survey of Student Engagement (NSSE) in North America and its introduction to a number of other countries (e.g., Australia, South Africa, Ireland, China, and more recently the UK), the NSSE-focused paradigm has obtained a dominant position in the existing literature. In North America alone, approximately six million students from over 1,600 institutions have completed the NSSE survey since 2000 (NSSE 2018). The NSSE model originally had five benchmarks ${ }^{2}$ to calibrate student engagement, which were later updated to the current model consisting of four themes and ten underpinning indicators (NSSE 2018):

\section{Academic Challenge}

- $\quad$ High-Order Learning

- $\quad$ Reflective and Integrative Learning

- Learning Strategies

- Quantitative Reasoning

Experiences with Faculty

- Student-Faculty Interaction

- Effective Teaching Practices

\section{Learning with Peers}

- Collaborative Learning

- Discussions with Diverse Others

\section{Campus Environment \\ - Quality of Interactions \\ - Supportive Environment}

Under this paradigm, a large body of literature, as summarised by Trowler \& Trowler (2010, pp. 8-9), has identified close links between student engagement and enhancement of various desirable student outcomes, for example, general abilities and critical thinking (Foubert and Grainger 2006; Shulman 2002), practical competence and skills transferability (Kuh 1993, 1995) and improved grades (Indiana University Centre for Postsecondary Research 2002), to name but a few.

In the Chinese context, the concept of student engagement was introduced along with the NSSE survey by a research team at Tsinghua University. After translation and cultural adaptation, the resultant NSSE-China, which was later extended into Chinese College Student Survey (CCSS), has been administered annually since 2009 (Zhang, Hu, and McNamara 2015). Accordingly, there has appeared an increasing amount of concomitant research related to NSSEChina/CCSS. However, although the idea of students' investment of time and effort in learning is not new for Chinese researchers, the concept of student engagement and the measurement of it through large scale surveys (i.e. student behaviour in relation to institutional practices) are new in the Chinese context and need more research (Ross, Cen, and Shi 2014). Moreover, as an imported concept, "student engagement" has more than one translation in Chinese, such as 参与度 (can yudu) and 学习性投入 (xue xi xing tou ru). The existence of multiple nuanced translations, to a certain degree, indicates an added complexity in the perceptions of this construct in China.

NSSE and its derivative surveys collect data about what students do, and measure it using benchmarks or scales. They have been very powerful in demonstrating the correlations between students' level of engagement and various desirable outcomes, and have enhanced the efficiency of organisations developing strategies and policies. However, there have also emerged critiques and warnings of the NSSE-focused paradigm. While acknowledging the overwhelming support for NSSE and its derivative surveys across the world, Solomonides (2013, p. 48) warns that the survey results need to be viewed with caution "as proxies for quality in learning and teaching". Moreover, "the survey items 'measure' engagement as conceptualised against pre-determined pedagogic practices", much of which is centred on what students do, rather than "how engagement is experienced by students" (ibid.). Thus tensions may arise due to the disparity between student engagement, as a potential proxy for student behaviour and pedagogy, and the measurement of it through NSSE type surveys with built-in norms gauging teaching and learning (Solomonides 2013). Furthermore, over-reliance on outcomes of such surveys in the process of making policies or strategies may increase the risk of institutions using the measurement means as management tools and performance indicators (Bryson 2014) or as educational targets for improvement (Solomonides 2013). As Strathern (1997, p. 308) argues, "when a measure becomes a target, it ceases to be a good measure". When institutions strive for better survey performances, they are putting the cart before the horse and losing their original intention of enhancing students' educational experience. Indeed, student engagement should be improved through surveys, but not for them. In addition, methodologically, some scholars (e.g., Lanasa et al. 2009; Porter 2011; Hagel et al. 2012) have also challenged the validity and reliability of NSSE type of surveys.

\section{B. Key Indicators for Successful Engagement}

Successful engagement does not take place of its own accord; it involves efforts from stakeholders at different levels. As direct participants and ultimate agents of engagement, students' perceptions and choices are apparently of prime importance. Students learn from what they do at university (Pike and Kuh 2005); their engagement is thus a process and product resulting from the synergistic interaction between motivation and active learning (Barkley 2017). Students

\footnotetext{
${ }^{2}$ The five benchmarks were: Level of Academic Challenge, Active \& Collaborative Learning, Study-Faculty Interaction, Supportive Campus Environment and Enriching Educational Experiences.
} 
"must invest time and effort into academic activities and practices ... that correlate highly with positive educational outcomes" (Bensimon 2009, p. xxiii).

Many researchers have also found that student-staff interaction is closely tied to student engagement (e.g., Tinto 2000; Umbach \& Wawrzynski 2005). Hu and Kuh (2002, p. 570) argue that staff "can make concrete links between what students are reading and discussing and other aspects of their lives". Coates (2005, p. 26) suggests that teaching staff should make themselves "available for consultation outside class time". Markwell (2007, p. 18) explicitly points to the need for staff engagement in various ways, such as encouraging interactions during class, requiring students to study in groups, using feedback to boost engagement, urging and stimulating students to master the content at a deeper level (i.e., understanding rather than memorising), relating their own research with teaching, participating in and supporting students' extracurricular activities, and so forth.

Furthermore, Markwell (2007) notes the importance of an inclusive campus environment, in which students of various backgrounds are able to engage on an equal basis, which is consistent with Barnacle \& Dall'Alba's (2017) opinion that the institution should promote students' engagement by helping them develop a capacity to care about others. Also, Kahu \& Nelson (2018) introduce the concept of educational interface through which institution and student efforts combine to boost student engagement. Coates (2005) suggests that institutions provide appropriate resources and opportunities to promote specific kinds of interactions. Moreover, relevant staff should also ensure that "what is enacted is of acceptable quality" (Kuh 2009b, p. 697). According to Kuh (2009a, p. 316), creating an engaging and inviting environment is not only an instrumental but a moral duty, which "behoves faculty and staff to create opportunities for all students to participate in ... high impact practices", such as "learning communities, student-faculty research, service learning, internships, study abroad, and capstone seminars or other culminating experiences". Providing an engaging environment is "not just the wise thing to do ... it is also the right thing to do (emphasis in original)" (Trowler 2010, p. 40).

\section{METHODS}

This paper reports part of the findings from a project on undergraduate student engagement, which was carried out at three sites, including a mathematics course in the UK, and a mathematics course and a Chinese language course in China. The two universities were comparable in terms of reputation in their country and other characteristics (e.g., size, urban location, range of subjects). Such a design enabled two key comparisons: the first, between two politically and culturally different countries viewed through the lens of mathematics, a highly internationalised and relatively culture neutral subject; and the second, between two very different courses, one from a science paradigm and one from an arts tradition (mathematics vs Chinese), in the same cultural context. Data were garnered using questionnaire, individual interview and group interview methods. Both students' and staff's points of view were sought. The project aimed to illuminate the characteristics of teaching, learning and student development, and, more generally, to contribute to clarifying the construct of student engagement in the higher education sector. The focus of this paper will be the survey findings emerging from the two courses in China. Other findings from the project can be found in Zhang and McNamara (2018).

Questionnaires were administered to all students on the three courses in China and the UK. The purpose was to identify general patterns in students' responses to the instrument and to spot any atypical aspects of their responses. At the Chinese university, 800 printed copies of the instrument were distributed (400 for each course) through the instructors $^{3}$ and 476 valid questionnaires were returned, of which 259 were from the mathematics course and 217 were from the Chinese language course, the overall response rate being $59.5 \%$.

The instrument was developed from two widely used questionnaires, the North American NSSE and the UK National Student Survey (NSS). NSS is a well-established national survey extensively administered across UK universities to collect information about teaching and learning. It is categorised as a survey of students' satisfaction with the quality of their courses; however, despite the scales of the survey (e.g., from definitely agree to definitely disagree), the content of the indicators and the specific items overlap much with those of NSSE. NSSE was utilised as the primary basis; and twenty-two items from NSS were incorporated as a supplement. The instrument was developed first in English and then translated into Chinese. The Chinese version also drew on NSSE-China to ensure the accuracy of translation. Both versions were culturally adapted and piloted. Additionally, as mentioned earlier, there are two frequently used Chinese translations of student engagement, i.e., 参与度 (can yu du) and 学习性投入 (xue xi xing tou ru). According to an earlier paper of ours (Zhang, Hu, and McNamara 2015), 参与度 (can yudu) was found to be a translation more equivalent to the English term, and was thus used in the Chinese version.

Exploratory factor analysis was conducted to scale students' responses to the questionnaires. We did not run a confirmatory analysis considering that certain original items from NSSE and NSS were deleted in the process of developing and culturally adapting the instrument, and as a result, an a priori model and the number of factors and the items loading on them were not known. The factor analysis was done with the Chinese dataset only, because the response rate from the UK students was not sufficient to garner a dataset of a comparable size. Notwithstanding, we

\footnotetext{
${ }^{3}$ This term may have varied connotations in different higher education systems. At the Chinese university in question, the responsibilities of this role mainly involve supporting students' non-academic needs and caring for their personal development.
} 
were fairly confident that the "structure" of the UK responses would be similar to those of the Chinese students as both version of the questionnaire instrument were developed primarily on the basis of NSSE, and both were culturally adapted to ensure that they were well received and understood in the two contexts respectively. This confidence was further reinforced when we did some confirmatory analyses with the UK dataset using the factors derived from the dataset in China; the results were positive, reassuring us about the reliability of the factors ${ }^{4}$.

The analysis was first attempted with the two datasets separately to see whether students on the two courses responded differently. Similar factor structures were identified; that is, a five-factor solution was found the most suitable for both datasets. Among the five factors, two of them subsumed exactly the same items; the majority of items loading on the other three factors were also the same. Therefore, we combined the two datasets and reran factor analysis with the whole dataset.

Models were then developed to find out the magnitude of each factor in predicting students' engagement and experiences (academic and non-academic). We hoped to derive insights into the roles that the five factors played, and, more broadly, to develop a better understanding of the dominant NSSE-focused paradigm. It is a common practice in research studies, particularly in those that are exploratory in nature and involve analysis of many variables, to identify "significant" variables using some statistical techniques and derive a "best fitting" and parsimonious model by including only the significant variables (Hutcheson 2012). However, Hutcheson (2012, p. 14) questions whether "[any] single regression model can adequately describe the relationships in this set of data"; according to him, a single model derived using a certain technique ignores competing models that may have been selected using a slightly different sample or another equally valid procedure, and thus introduces difficulties for the researcher to adequately describe the research findings and generalise them to a larger population (Hutcheson 2012). Therefore, as suggested by Hutcheson, we adopted the strategy of multiple model selection and compared competing models so as to better understand the magnitude of each factor in predicting students' engagement and experiences. When responding to the questionnaires, students were asked to rate their perceived extent of engagement, academic experience and non-academic experience. To develop models, we used these three items as outcome variables, and the five factors and two background variables, School and Year, as explanatory variables. In the next section, we will first report students' ratings of the three outcome variables across the three courses, and then move on to the factoring and modelling results.

\section{RESUlts}

\section{A. Students' Ratings of Their Engagement and Experiences (Academic and Non-academic)}

Fig. 1 illustrates the score ranges and means of the three student cohorts. The UK dataset indicated that students' extent of engagement scores ranged from three to nine (on a scale of 1-10), with a mean of 6.26 and a standard deviation (spread of the scores from the mean) of 1.7. The corresponding engagement scores for the mathematics course in China ranged from one to ten with a mean of 7.09 and a standard deviation of 1.54. For the Chinese language course, the mean was at 6.72 and the standard deviation was 1.52. Overall, engagement scores at the Chinese university averaged a mean of 6.92 on a range of one to ten with a standard deviation of 1.54.

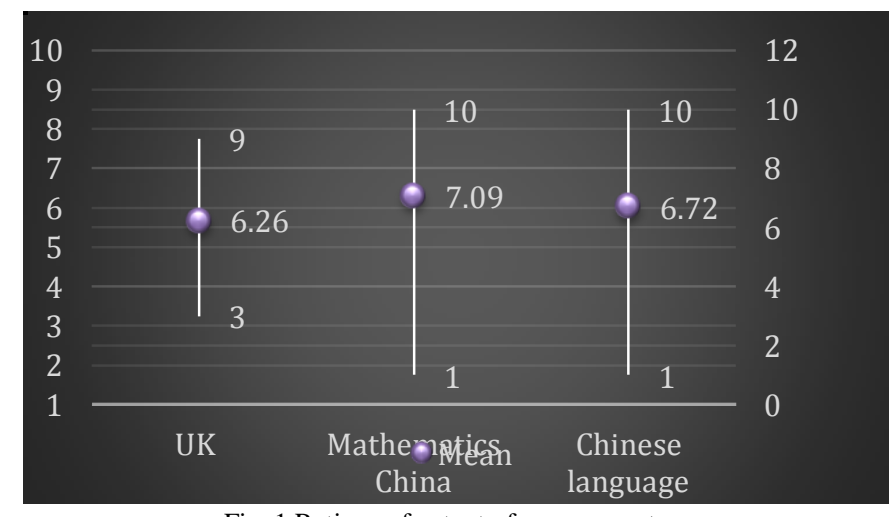

Fig. 1 Ratings of extent of engagement

In respect of students' academic experience, however, the figures were turned. Mathematics students in the UK rated their academic experience highest, with a mean of 3.35 on a four-point scale. This compared to 3.03 on the mathematics course in China and to 2.90 on the Chinese language course. The Chinese language students were more positive when it came to their non-academic experience, however, with a mean of 2.91 against the Chinese mathematics course 2.86 and the UK mathematics students 3.10. Fig. 2 and Fig. 3 illustrate the ratings.

\footnotetext{
${ }^{4}$ In view of the flaws of the UK dataset, we did not include these results in this paper lest they appeared more robust than they were and misled readers.
} 


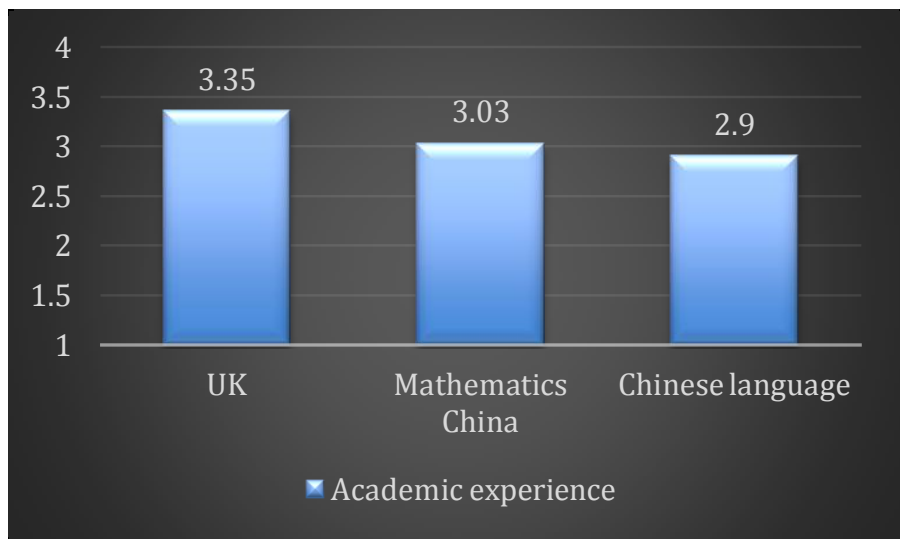

Fig. 2 Ratings of academic experience

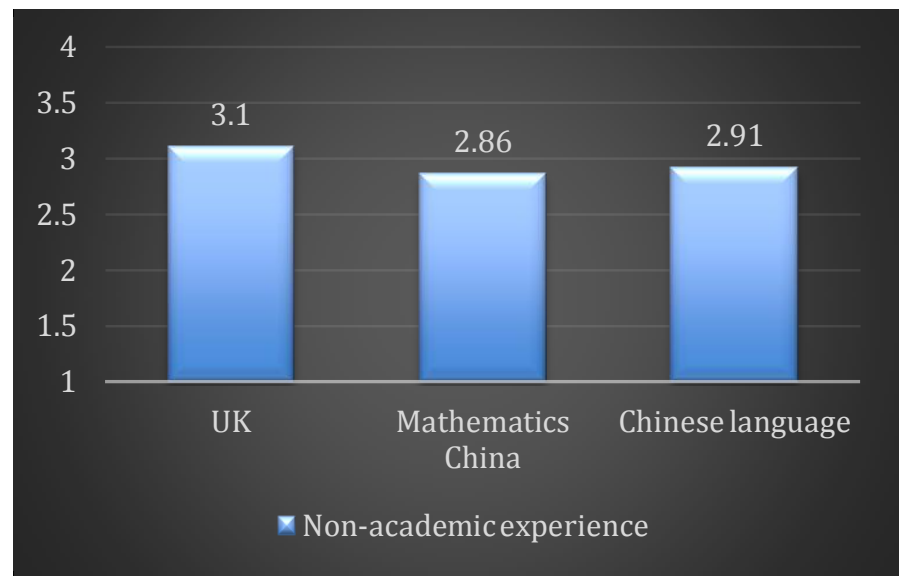

Fig. 3 Ratings of non-academic experience

\section{B. Factor Analysis}

An initial principal axis factor analysis was run on 66 items with oblique rotation (direct oblimin). To enhance the validity and stability of factors, a total of 12 items were eliminated during several steps. Both the statistical and the conceptual/practical implications of these items were considered when decisions were made on item deletion. By comparing the item loading tables (after rotation), the one with five factors was found to have the best factor structure (in terms of item loadings and crossloadings and the number of items under each factor). The five factors were named following a process of item inspection and analysis and in conjunction with relevant student engagement literature (Lanasa, Cabrera, and Trangsrud 2009): Factor 1 - Effective Teaching Practices (ETP); Factor 2 - Personal Development (PD); Factor 3 - Supportive Campus Environment (SCE); Factor 4 - Collaborative, Reflective \& Integrative Learning (CRIL); and Factor 5 - Quality of Interactions (Student-Staff) (QI). The five factors explained 53\% of the variance. All items but three had primary loadings over 0.44 ; no items except one had crossloadings above 0.3 .

\section{Modelling Students' Engagement and Experiences}

On the basis of the five factors, we developed models against the three outcome variables: extent of engagement, academic experience and non-academic experience. Models about students' extent of engagement will be reported in detail for an illustrative purpose; results about the other two outcome variables will be presented briefly.

Extent of engagement

Fig. 4 and Fig. 5 illustrate the subsets of models about students' extent of engagement, which were generated using the R software 5 and ranked according to two specific criteria, adjr2 (Adjusted R-squared) and bic (Bayesian Information Criterion), which $\mathrm{R}$ used in this case to display competing models. The black blocks indicate variables that were included in the models and the white blocks indicate those that were not. The best models were listed on the top of both graphs with the biggest adjr2 score or smallest bic score.

\footnotetext{
${ }^{5} \mathrm{R}$ is a free software environment for statistical computing and graphics.
} 


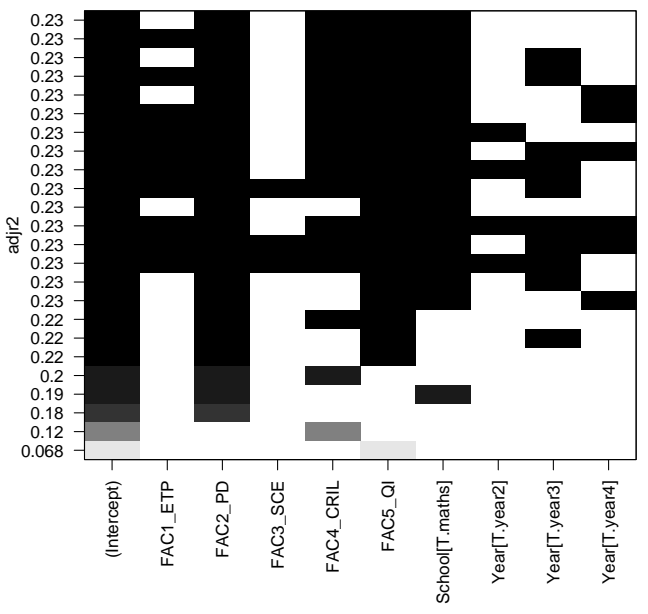

Fig. 4 Competing models (adjr2)

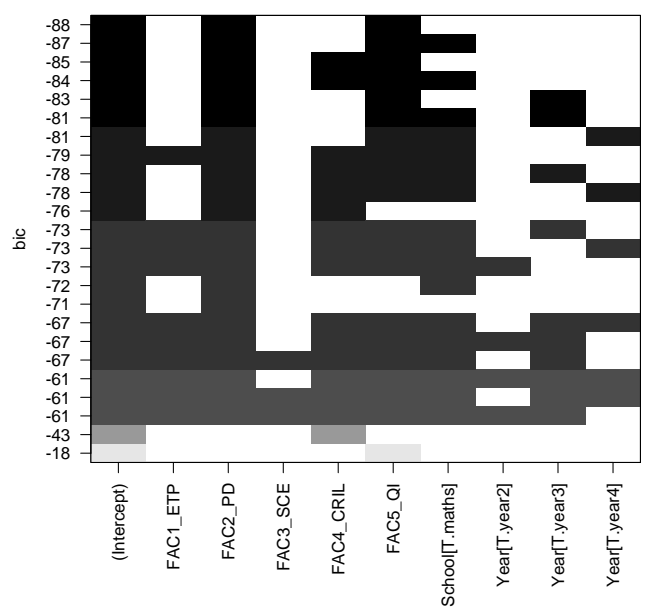

Fig. 5 Competing models (bic)

Although the two graphs look slightly different, they actually provide a consistent picture. Both graphs highlight Personal Development (PD) and Quality of Interactions (QI), as they enter into most of the models. Collaborative, Reflective and Integrative Learning (CRIL) and School may also be significant predictors according to both criteria but may be slightly less important compared with $P D$ and QI. Year and Supportive Campus Environment (SCE) seem to be insignificant for predicting students' extent of engagement. This way of assessing the variables provides more convincing evidence of the importance of a certain variable in the population than merely quoting a single model (Hutcheson 2012). In a single model, if a variable is missing, it will be unclear whether it will enter a model if the sample is slightly different or another equally good technique is used to derive the model (Hutcheson 2012). This way is important also because it informs the next step of the analyses that focus on the impacts of the explanatory variables on the outcome variable.

The top three lines on each graph were selected for test ${ }^{6}$. To find out whether the two background variables were mediated by other explanatory variables (i.e., the five factors), a model containing only School and Year was tested. In each model, $Y$ stands for the outcome variable, $\alpha$ is the intercept, is $\beta$ is the coefficient that represents the rate of change of an explanatory variable.

adjr2

(1) $Y=\alpha+\beta_{1} P D+\beta_{2} C R I L+\beta_{3} Q I+\beta_{4}$ School

(2) $Y=\alpha+\beta_{1} E T P+\beta_{2} P D+\beta_{3} C R I L+\beta_{4} Q I+\beta_{5}$ School

(3) $Y=\alpha+\beta_{1} P D+\beta_{2}$ CRIL $\beta_{3} Q I+\beta_{4}$ School $+\beta_{5-7}$ Year

bic

(4) $Y=\alpha+\beta_{1} P D+\beta_{2} Q I$

(5) $Y=\alpha+\beta_{1} P D+\beta_{2} Q I+\beta_{3}$ School

(6) $Y=\alpha+\beta_{1} P D+\beta_{2} C R I L+\beta_{3} Q I$

\section{A Model Containing Only Background Variables (For Reference)}

(7) $Y=\alpha+\beta_{1}$ School $+\beta_{2-4}$ Year

Students' extent of engagement was rated on a Likert scale of 1-10, which meant that this outcome variable could be treated as a continuous variable in the regression (Rhemtulla, Brosseau-Liard, and Savalei 2012). Assumptions of multicollinearity ${ }^{7}$, linearity, randomness, homoscedasticity and normality were checked and the Generalised Linear Model (GLM) was run with the selected models. Table 1 illustrates the effects of individual variables by comparing the models. Detailed parameters including t-statistics of each model are presented in Table 2.

\footnotetext{
${ }^{6}$ It should be noted that these models were selected and tested for an illustrative purpose and they were not necessarily the only 'best fitting' models.

${ }^{7}$ Derived from the exploratory factor analysis, the five factors were not expected to correlate strongly to the extent of causing high multicollinearity.
} 
TABLE 1

ASSESSING VARIABLE SIGNIFICANCE By COMPARING MODEL DEVIANCES (EXTENT OF ENGAGEMENT)

\begin{tabular}{|c|c|c|c|c|c|}
\hline Model & Residual & Deviance & $\mathrm{df}$ & F-value & $\mathrm{P}$-value \\
\hline $\begin{array}{l}\text { Determining the effect of model (4) } \\
Y=\alpha \\
Y=\alpha+\beta_{1} P D+\beta_{2} Q I\end{array}$ & $\begin{array}{l}970.39 \\
753.54\end{array}$ & 216.85 & 2 & 59.86 & 0.000 \\
\hline $\begin{array}{l}\text { Determining the effect of CRIL } \\
\text { (model (4) vs model (6)) } \\
Y=\alpha+\beta_{1} P D+\beta_{2} Q I \\
Y=\alpha+\beta_{I} P D+\beta_{2 C} C R I L+\beta_{3} Q I \\
\end{array}$ & $\begin{array}{l}753.54 \\
747.69 \\
\end{array}$ & 5.853 & 1 & 3.248 & 0.072 \\
\hline $\begin{array}{l}\text { Determining the effect of School } \\
\text { (model (4) vs model (5)) } \\
Y=\alpha+\beta_{1} P D+\beta_{2} Q I \\
Y=\alpha+\beta_{1} P D+\beta_{2} Q I+\beta_{3} \text { School }\end{array}$ & $\begin{array}{r}753.54 \\
745.12 \\
\end{array}$ & 8.416 & 1 & 4.687 & 0.031 \\
\hline $\begin{array}{l}\text { Determining the effect of Year } \\
\text { (model (1) vs model (3)) } \\
Y=\alpha+\beta_{1} P D+\beta_{2} C R I L+\beta_{3} Q I+\beta_{4} \text { School } \\
Y=\alpha+\beta_{1} P D+\beta_{2} C R I L+\beta_{3} Q I+\beta_{4} \text { School }+\beta_{5-7} \text { Year }\end{array}$ & $\begin{array}{r}739.27 \\
737.98 \\
\end{array}$ & 1.289 & 3 & 0.239 & 0.869 \\
\hline $\begin{array}{l}\text { Determining the effect of ETP } \\
\text { (model (1) vs model (2)) } \\
Y=\alpha+\beta_{1} P D+\beta_{2} C R I L+\beta_{3} Q I+\beta_{4} \text { School } \\
Y=\alpha+\beta_{1} E T P+\beta_{2} P D+\beta_{3} C R I L+\beta_{4} Q I+\beta_{5} \text { School }\end{array}$ & $\begin{array}{r}739.27 \\
737.95 \\
\end{array}$ & 1.326 & 1 & 0.742 & 0.389 \\
\hline
\end{tabular}

TABLE 2

PARAMETERS OF COMPETING MODELS (EXTENT OF ENGAGEMENT)

\begin{tabular}{|c|c|c|c|c|c|}
\hline Model & & Estimate & Std. Error & t-value & Sig. \\
\hline \multirow[t]{5}{*}{ (1) } & Intercept & 6.781 & 0.095 & 71.028 & 0.000 \\
\hline & PD & 0.556 & 0.083 & 6.741 & 0.000 \\
\hline & CRIL & 0.159 & 0.087 & 1.81 & 0.071 \\
\hline & QI & 0.285 & 0.077 & 3.696 & 0.000 \\
\hline & School (T. mathematics) & 0.285 & 0.131 & 2.171 & 0.031 \\
\hline \multirow[t]{6}{*}{ (2) } & Intercept & 6.789 & 0.096 & 70.824 & 0.000 \\
\hline & ETP & -0.071 & 0.083 & -0.862 & 0.389 \\
\hline & PD & 0.572 & 0.084 & 6.768 & 0.000 \\
\hline & CRIL & 0.184 & 0.092 & 1.991 & 0.047 \\
\hline & QI & 0.297 & 0.078 & 3.789 & 0.000 \\
\hline & School (T. mathematics) & 0.272 & 0.132 & 2.057 & 0.040 \\
\hline \multirow[t]{8}{*}{ (3) } & Intercept & 6.795 & 0.133 & 51.219 & 0.000 \\
\hline & PD & 0.554 & 0.084 & 6.581 & 0.000 \\
\hline & CRIL & 0.155 & 0.088 & 1.763 & 0.079 \\
\hline & QI & 0.290 & 0.078 & 3.723 & 0.000 \\
\hline & School (T. mathematics) & 0.270 & 0.142 & 1.894 & 0.059 \\
\hline & Year (T. Year 2) & 0.028 & 0.170 & 0.164 & 0.870 \\
\hline & Year (T. Year 3) & -0.116 & 0.189 & -0.613 & 0.540 \\
\hline & Year (T. Year 4) & 0.055 & 0.204 & 0.270 & 0.788 \\
\hline \multirow[t]{3}{*}{ (4) } & Intercept & 6.931 & 0.066 & 105.392 & 0.000 \\
\hline & PD & 0.639 & 0.070 & 9.064 & 0.000 \\
\hline & QI & 0.347 & 0.072 & 4.789 & 0.000 \\
\hline \multirow[t]{4}{*}{ (5) } & Intercept & 6.780 & 0.096 & 70.823 & 0.000 \\
\hline & PD & 0.635 & 0.070 & 9.058 & 0.000 \\
\hline & QI & 0.333 & 0.072 & 4.600 & 0.000 \\
\hline & School (T. mathematics) & 0.285 & 0.131 & 2.165 & 0.031 \\
\hline \multirow[t]{4}{*}{ (6) } & Intercept & 6.932 & 0.066 & 105.689 & 0.000 \\
\hline & PD & 0.559 & 0.083 & 6.749 & 0.000 \\
\hline & CRIL & 0.158 & 0.088 & 1.802 & 0.072 \\
\hline & QI & 0.298 & 0.077 & 3.872 & 0.000 \\
\hline \multirow{5}{*}{ (7) } & Intercept & 6.750 & 0.145 & 46.650 & 0.000 \\
\hline & School & 0.415 & 0.157 & 2.641 & 0.009 \\
\hline & Year (T. Year 2) & -0.175 & 0.186 & -0.942 & 0.346 \\
\hline & Year (T. Year 3) & -0.186 & 0.207 & -0.900 & 0.369 \\
\hline & Year (T. Year 4) & 0.198 & 0.224 & 0.884 & 0.377 \\
\hline
\end{tabular}

As is shown in Table 1, Model (4) is significantly better than the model with only an intercept, and $P D$ and $Q I$ enter into all the six selected models, both of which indicate that these two variables play a highly crucial role in predicting the outcome variable; School is also significant $(\mathrm{p}=0.031)$ so may be another important variable. In contrast, CRIL, Effective Teaching Practices (ETP) and Year seem to be less important judged from their p-values. The t-statistics in Table 2 show a consistent picture. $P D$ and $Q I$ are highly significant across all six models, while ETP and Year are insignificant in all the models that they enter. School is significant in three models and marginally insignificant $(\mathrm{p}=$ 0.059) in a fourth one; whilst CRIL is significant in one model but insignificant in the other three. Additionally, the 
different significance values of School and Year in Model (7) and other models indicate that these two background variables may have been slightly mediated by one or more of the five factors. In a nutshell, both the graphs and statistics indicate that $P D, Q I$ and School are powerful predictors of students' extent of engagement.

Academic and non-academic experiences

Models about students' academic and non-academic experiences were developed in a similar way. The two outcome variables were measured on a Likert scale of 1-4, indicating that they were (ordered) categorical data, so either the Proportional Odds Model (when the proportional odds assumption was met) or otherwise the Multinomial Model was utilised.

By comparing the competing models and reviewing the model parameters, it was found that $P D, C R I L$ and $Q I$ were highly significant explanatory variables in describing students' academic experience; on the other hand, ETP, SCE and School, which could be categorised as contextual influences, were insignificant in all the models selected for test. Also, the model that contained only School and Year showed that the former was a significant predictor of students' academic experience, but it was insignificant when appearing together with the factor variables. This indicated that School might have been mediated by the factor variables. In fact, according to the qualitative data, students on the two courses did report rather different learning experiences, in aspects such as level of academic challenge and ways of assessment (see Zhang and McNamara (2018) for details). Thus, School may be another important predictor along with PD, CRIL and $Q I$, though its magnitude may not be so high as the latter three. As for students' non-academic experience, the graphs and statistics indicated that $P D, C R I L, Q I$ and $S C E$ were important predictors of the outcome variable, while ETP and School appeared to be insignificant.

\section{DISCUSSION}

The statistics indicated that overall students at the Chinese university considered themselves more engaged than their UK counterparts, while the latter enjoyed their academic and non-academic experiences more than the former. This interesting and seemingly contradictory phenomenon reflected, at least in part, the disparity between students' behavioural engagement and their enjoyment in learning. It was found that there were different assessment systems at the two universities. At the Chinese university, students were assessed both academically (90\%) and in terms of personal development (10\%), and they were ranked according to their total scores. As a result, many students worked very hard but did not necessarily enjoy the learning process; some people selected activities carefully only to maximise their development scores. On the other hand, students at the UK university had more flexibility in choosing modules and had free choices of co-curricular/extracurricular activities according to personal interest and preference, thus more likely to engage at a deeper (e.g., cognitive and psychological) level and enjoy their university experience. The ratings also showed that at the Chinese university, the mathematics students had slightly better engagement and academic experience; whilst the language students were more positive about their non-academic experience. Owing to the sharp difference between the two subjects, students were assessed in dissimilar manners (examinations vs. assignments); and learning on the mathematics course was more challenging and thought-provoking, which significantly reduced students' time for various activities.

The factor structure derived in this paper accords well with the NSSE and NSS structures (NSS 2018; NSSE 2018), with four factors consistent with the NSSE themes, and all five factors in line with the NSS indicators. It can be seen in Table 3 that Personal Development, which was found to be highly significant in predicting students' extent of engagement and experiences, is missing in the NSSE structure. Also, as we have presented in Zhang and McNamara (2018), this five-factor structure subsumes 23 indicators emerging from the qualitative data, thus providing an overarching perspective to understand students' engagement and experiences.

TABLE 3

THE FIVE-FACTOR STRUCTURE VS. NSSE \& NSS STRUCTURES

\begin{tabular}{|c|c|c|}
\hline This research & NSSE (US) & NSS (UK) \\
\hline $\begin{array}{l}\text { Collaborative, Reflective \& } \\
\text { Integrative Learning }\end{array}$ & $\begin{array}{ll}\text { ACADEMIC CHALLENGE } \\
\text { - } & \text { High-Order Learning } \\
\text { - } & \text { Reflective \& Integrative Learning } \\
\text { - } & \text { Learning Strategies } \\
\text { - } & \text { Quantitative Reasoning } \\
\text { LEARNING WITH PEERS } \\
\text { - } & \text { Collaborative Learning } \\
\text { - } & \text { Discussions with Diverse Others }\end{array}$ & $\begin{array}{ll}- & \text { Learning opportunities } \\
\text { - } & \text { Learning community }\end{array}$ \\
\hline Effective Teaching Practices & $\begin{array}{ll}\text { EXPERIENCES WITH FACULTY } \\
& \text { Student-Faculty Interaction } \\
\bullet & \text { Effective Teaching Practices }\end{array}$ & $\begin{array}{ll}- & \text { The Teaching of My Course } \\
- & \text { Assessment and Feedback }\end{array}$ \\
\hline $\begin{array}{l}\text { Quality of Interactions } \\
\text { Supportive Campus } \\
\text { Environment }\end{array}$ & $\begin{array}{ll}\text { CAMPUS ENVIRONMENT } \\
-\quad \text { Quality of Interactions } \\
\text { - } & \text { Supportive Environment }\end{array}$ & $\begin{array}{ll}\bullet & \text { Academic Support } \\
\bullet & \text { Learning Resources } \\
\text { - } & \text { Organisation and } \\
\text { Management }\end{array}$ \\
\hline Personal Development & & Personal Development \\
\hline
\end{tabular}


Moreover, the model statistics inform us about which factors are of magnitude in describing students' perceived extent of engagement, academic experience and non-academic experience. Table 4 summarises the significant factors that we identified in the modelling process. It is evident that $P D$ and $Q I$ are of paramount importance, indicating that students were well aware of how well they had developed in various aspects and related it directly with the quality of their personal engagement and experiences. One of the contributing reasons might be the aforementioned assessment system, which took personal development scores into account and in turn raised students' awareness of all-round development. Also, as the interview data indicated, students' interaction with staff could considerably promote their engagement with learning and other activities. This could explain why $Q I$ was another highly significant predicator. The collocation of the three factors that significantly influence students' academic experience (PD, CRIL and $Q I)$ makes sense considering that all of them involve students as the direct agent. By engaging with academic activities and interacting with course tutors and peers, students might achieve development in various aspects (such as critical thinking and communication); and how much they enjoyed this process might to a large extent affect their rating of personal academic experience. It was also interesting that CRIL was found to influence students' non-academic experience. According to the qualitative interview data, many students, particularly those on the mathematics course had to spend much time out of class digesting the lecture content and did not have many opportunities to socialise or participate in extracurricular activities. With respect to the background variable School, due to the contrasting difference between the two subjects and the dissimilar teaching and assessment practices on the two courses, it was comprehensible that School played a significant role in mediating students' engagement and academic experience. For instance, closed-book examinations were the predominant form of assessment on the mathematics course and exerted much pressure on students, especially those who wanted to achieve good results; contrastingly, students on the Chinese language course were mainly assessed through assignments and were more likely to have flexibility in learning and enjoy the process (see Zhang and McNamara (2018) for details).

TABLE 4

A SUMMARY OF SIGNIFICANT FACTORS IN THE MODELS

\begin{tabular}{|l|c|c|c|}
\hline & $\begin{array}{c}\text { Extent of } \\
\text { Engagement }\end{array}$ & $\begin{array}{c}\text { Academic } \\
\text { experience }\end{array}$ & $\begin{array}{c}\text { Non-academic } \\
\text { experience }\end{array}$ \\
\hline Personal Development (PD) & $\checkmark$ & $\checkmark$ & $\checkmark$ \\
\hline Quality of Interactions (QI) & $\checkmark$ & $\checkmark$ & $\checkmark$ \\
\hline Collaborative, Reflective and Integrative Learning (CRIL) & & $\checkmark$ & $\checkmark$ \\
\hline Supportive Campus Environment (SCE) & & $\checkmark$ & $\checkmark$ \\
\hline School & $\checkmark$ & $\checkmark$ & $\checkmark$ \\
\hline
\end{tabular}

These findings are consistent with a number of studies in the literature. For example, to benefit from engagement, students need to be motivated and actively invest time and energy into activities related to their course (Bensimon 2009; Barkley 2017) and interact with peers in challenging and productive learning activities (Coates 2005) (cf. Factor Collaborative, Reflective \& Integrative Learning). Engagement is also connected with development in aspects such as organising, communicative and reflective skills (Coates 2005) (cf. Factor Personal Development); high-quality studentstaff interaction was found to link closely with student engagement (e.g., Tinto 2000; Umbach \& Wawrzynski 2005) (cf. Quality of Interactions). Institutions should perform their function fully in the educational interface (Kahu and Nelson 2018); this could include providing students with appropriate resources, opportunities and support services (Coates 2005), deploying these resources and organise the opportunities and services in a proper way (Kuh 2007) (e.g. sufficient space for students to work collaboratively (Coates 2005) and student-staff research (Kuh 2009b), and creating an inclusive and engaging environment (Markwell 2007), in order to enhance students' engagement and experiences at university (cf. factors Supportive Campus Environment and Quality of Interactions). Some scholars (e.g., Kuh 2009a, 697) argue that courses, particularly teaching practices, that are of 'high impact', should be ensured to have the desired effects. Surprisingly, Effective Teaching Practices was found to have a lower order of magnitude and did not emerge in the models as a significant predictor of students' engagement nor their experiences. Given the empirical data that we have collected, we think a possible reason might be that lectures on the two courses were generally teacher-centred and there was little student-course tutor interaction during and after class; nevertheless, it would be interesting to further explore this phenomenon in the future. Finally, to illustrate the magnitude of these factors and the multi-layer influences that they exerted on students' engagement and experiences, we generated a diagram (Fig. 6), which consisted of multiple ovals; and the closer a factor is to the core oval, the stronger impacts it may have. 


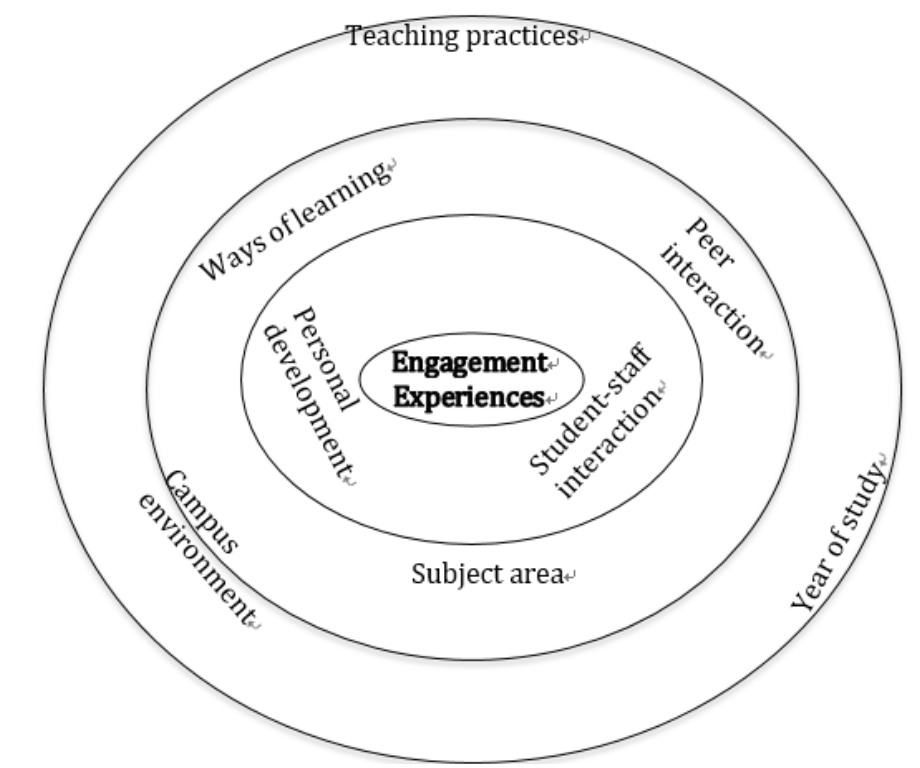

Fig. 6 Magnitude of the factors in relation to students' engagement and experiences

\section{CONCLUSION}

In this paper we focused on students' engagement and experiences on two courses (mathematics and Chinese language) at a Chinese university. Students' ratings indicated that those on the mathematics course were slightly more engaged and had marginally better academic experience; whilst those on the language course were more satisfied about their non-academic experience. Five factors emerged from the exploratory factor analysis: Effective Teaching Practices, Personal Development, Supportive Campus Environment, Collaborative, Reflective \& Integrative Learning and Quality of Interactions (Student-Staff). Models developed on the basis of the five factors and the two background variables (School and Year) informed us about the magnitude of each factor in explaining students' engagement and experiences (academic and non-academic), which is missing in both the NSSE and the NSS structures, and thus added interpretative power to understanding the mechanism of how the factors function together to influence students' engagement and experiences. Specifically, Personal Development and Quality of Interactions (Student-Staff) were found to be the foremost factors influencing student engagement and experiences; subject area was key to students' engagement and academic experience; Collaborative, Reflective \& Integrative Learning was crucial for students' academic and nonacademic experiences; and Supportive Campus Environment was essential for their non-academic experience. Effective Teaching Practices was found to be an insignificant explanatory variable.

Informed by these findings, future attention could be focused on the core influences (as is shown in Fig. 6) so that students could have better quality engagement and experiences at university. For instance, interactions between students and staff could be strengthened to enhance the dynamics between the two groups. Course tutors could take such measures as finishing the lecture with questions that trigger discussion, incorporating student response systems in the lecture (e.g., clickers), introducing group projects, presentations or task-based learning to the lecture (Allen \& Tanner 2005 drawn on in Gasiewski et al. 2012), and providing guidance (face-to-face or online) out of normal teaching hours and in response to students' individual needs (Kuh and $\mathrm{Hu}$ 2001). Instructors, who are responsible for supporting students' non-academic needs and caring for their personal development (see Footnote 3), could have more effective and frequent meetings with students to guide, monitor and support their progress in learning, and provide them with necessary pastoral care. In addition, various types of interesting, engaging activities, either co-curricular or extracurricular, could be initiated and peer interaction should be encouraged in order to help students develop transferrable skills (e.g., critical thinking, communicative, time management) that they could apply in academic learning and other aspects of their life. Also, considering that subject area may have an impact on students' engagement and academic experience, ways of teaching and assessment within each school could be adjusted to promote students' engagement with the course and allow them to enjoy the process of learning. After all, to what extent they enjoy the four years at university is equally important as (if not more important than) what they do there.

\section{REFERENCES}

[1] Allen, D., and K. Tanner. (2005). Infusing Active Learning into the Large-Enrollment Biology Class: Seven Strategies, from the Simple to Complex. Cell Biology Education, 4 (4),262-268.

[2] Astin, A. W. (1984). Student Involvement: A Developmental Theory for Higher Education. Journal of College Student Development, 25, 297-308. 
[3] Barkley, E. F. (2017). Terms of Engagement: Understanding and Promoting Student Engagement in Today's College Classroom. In K. Matsushita (Ed.), Deep Active Learning: Toward Greater Depth in University Education. Singapore: Springer, 35-57.

[4] Barnacle, R., and G. Dall'Alba. (2017). Committed to Learn: Student Engagement and Care in Higher Education. Higher Education Research and Development, 36 (7), 1326-1338.

[5] Bensimon, E. M. (2009). Foreword. In S. R. Harper and S. J. Quaye (Eds.), Student Engagement in Higher Education. New York and London: Routledge, xxi-xxvi.

[6] Bryson, C. (2014). Clarify the Concept of Student Engagement. In C. Bryson (Ed.), Understanding and Developing Student Engagement. Oxon UK: Routledge, 1-22.

[7] Coates, H. (2005). The Value of Student Engagement for Higher Education Quality Assurance. Quality in Higher Education, $11(1), 25-36$.

[8] Ewell, P. T., and D. P. Jones. (1996). Indicators of "Good Practice" in Undergraduate Education: A Handbook for Development and Implementation. Boulder, CO: National Center for Higher Education Management Systems.

[9] Foubert, J. D., and L. U. Grainger. (2006). Effects of Involvement in Clubs and Organizations on the Psychosocial Development of First-Year and Senior College Students. NASPA Journal, 43 (1), 166-182.

[10] Gasiewski, J. A., M. K. Eagan, G. A. Garcia, S. Hurtado, and M. J. Chang. (2012). From Gatekeeping to Engagement: A Multicontextual, Mixed Method Study of Student Academic Engagement in Introductory STEM Courses. Research in Higher Education, 53, 229-261.

[11] Hagel, P., R. Can, and M. Devlin. (2012). Conceptualising and Measuring Student Engagement through the Australasian Survey of Student Engagement (AUSSE): A Critique. Assessment and Evaluation in Higher Education, 37 (4), 475-486.

[12] Hu, S., and G. D. Kuh. (2002). Being (Dis)Engaged in Educationally Purposeful Activities: The Influences of Student and Institutional Characteristics. Research in Higher Education, 43 (5), 555-576.

[13] Hutcheson, G. D. (2012). Statistical Model Selection. In L. Moutinho and K-H Huarng (Eds.), Quantitative Modelling in Marketing and Management, London: World Scientific, 91-113.

[14] Indiana University Centre for Postsecondary Research. (2002). From Promise to Progress: How Colleges and Universities Are Using Student Engagement Results to Improve Collegiate Quality. Bloomington, IN: Indiana Center for Postsecondary Research.

[15] Kahu, E. R., and K. Nelson. (2018). Student Engagement in the Educational Interface: Understanding the Mechanisms of Student Success. Higher Education Research and Development, 37 (1), 58-71.

[16] Kuh, G. D. (1993). In Their Own Words: What Students Learn Outside the Classroom. American Educational Research Journal, 30 (2), 277-304.

[17] Kuh, G. D. (1995). The Other Curriculum: Out-of-Class Experiences Associated with Student Learning and Personal Development. Journal of Higher Education, 66 (2), 123-155.

[18] Kuh, G.D. (2007). How to Help Students Achieve. Chronicle of Higher Education, 53 (41), 12-13.

[19] Kuh, G. D. (2009a). Afterword. In S.R. Harper and S.J. Quaye (Eds.), Student Engagement in Higher Education. New York and London: Routledge, 313-318.

[20] Kuh, G. D. (2009b). What Student Affairs Professionals Need to Know about Student Engagement. Journal of College Student Development, 50 (6), 683-706.

[21] Kuh, G. D., and S. Hu. (2001). The Effects of Student Faculty Interaction in the 1990s. Review of Higher Education, 24 (3), 309-332.

[22] Lanasa, S. M., A. F. Cabrera, and H. Trangsrud. (2009). The Construct Validity of Student Engagement: A Confirmatory Factor Analysis Approach. Research in Higher Education, 50, 315-332.

[23] Markwell, D. (2007). The Challenge of Student Engagement. University of Western Australia, 30-31 January. http://www.catlyst.catl.uwa.edu.au/catlyst/archive/2007/1/don_markwell. (accessed 20/03/2015).

[24] Merwin, J. C. (1969). Historical View of Changing Concepts of Evaluation. In R. L. Tyler (Ed.), Educational Evaluation: New Roles, New Methods (68th Yearbook of the National Society for the Study of Education, Part II). Chicago: University of Chicago Press, 6-25.

[25] NSS. (2018). About the NSS. https://www.thestudentsurvey.com/about.php. (accessed 28/03/2019).

[26] NSSE. (2015). About NSSE. http://nsse.iub.edu/html/about.cfm. (accessed 16/04/2015).

[27] NSSE. (2018). Engagement Indicators. http://nsse.indiana.edu/html/engagement_indicators.cfm. (accessed 10/12/2018).

[28] Pace, C. R. (1980). Measuring the Quality of Student Effort. Current Issues in Higher Education, 2, 10-16.

[29] Pace, C. R. (1984). Measuring the Quality of College Student Experiences: An Account of the Development and Use of the College Student Experiences Questionnaire. Los Angeles: Higher Education Research Institute.

[30] Pike, G. R., and G. D. Kuh. (2005). A Typology of Student Engagement for American Colleges and Universities. Research in Higher Education, 46 (2), 185-209.

[31] Porter, S. R. (2011). Do College Student Surveys Have Any Validity? The Review of Higher Education, 35 (1), $45-76$.

[32] Rhemtulla, M., P. E. Brosseau-Liard, and V. Savalei. (2012). When Can Categorical Variables Be Treated as Continuous? A Comparison of Robust Continuous and Categorical SEM Estimation Methods under Suboptimal Conditions. Psychological Methods, 17(3), 354-373.

[33] Ross, H., Y. Cen, and J. Shi. (2014). Engaging Students in China. In H. Coates and A. C. McCormick (Eds.), Engaging University Students: International Insights from System-Wide Studies. Singapore: Springer, 93-108.

[34] Shulman, L. S. (2002). Making Differences: A Table of Learning. Change, 34 (6), 35-44.

[35] Solomonides, I. (2013). A Relational and Multidimensional Model of Student Engagement. In E. Dunne and D. Owen (Eds.), The Student Engagement Handbook: Practice in Higher Education. Bingley, UK: Emerald, 43-58.

[36] Strathern, M. (1997). 'Improving Ratings': Audit in the British University System. European Review, 5 (3): $305-321$.

[37] Tinto, V. (1993). Leaving College: Rethinking the Causes and Cures of Student Attrition (2nd edn). Chicago: University of Chicago Press. 
[38] Tinto, V. (2000). Linking Learning and Leaving: Exploring the Role of the College Classroom in Student Departure. In J. M. Braxton (Ed.), Reworking the Student Departure Puzzle. Nashville: Vanderbilt University Press, 81-94.

[39] Trowler, P. (2015). Student Engagement, Ideological Contest and Elective Affinity: The Zepke Thesis Reviewed. Teaching in Higher Education, 20 (3), 328-339.

[40] Trowler, V. http://www.heacademy.ac.uk/assets/York/documents/ourwork/studentengagement/StudentEngagementLiteratureReview.pdf.

[41] Trowler, V., and P. Trowler. (2010). Student Engagement Evidence Summary. http://www.heacademy.ac.uk/assets/York/documents/ourwork/studentengagement/StudentEngagementEvidenceSummary.pdf. (accessed 26/05/2015).

[42] Umbach, P. D., and M. R. Wawrzynski. (2005). Faculty Do Matter: The Role of College Faculty in Student Learning and Engagement. Research in Higher Education, 46 (2), 153-184.

[43] Wolf-Wendel, L., K. Ward, and J. Kinzie. (2009). A Tangled Web of Terms: The Overlap and Unique Contribution of Involvement, Engagement, and Integration to Understanding College Student Success. Journal of College Student Development, 50 (4), 407-428.

[44] Zepke, N. (2014). Student Engagement Research in Higher Education: Questioning an Academic Orthodoxy. Teaching in Higher Education, 19 (6), 697-708.

[45] Zepke, N. (2015). What Future for Student Engagement in Neo-Liberal Times? Higher Education, 69, 693-704.

[46] Zhang, Z., W. Hu, and O. McNamara. (2015). Undergraduate Student Engagement at a Chinese University: A Case Study. Educational Assessment, Evaluation and Accountability, 27 (2), 105-127.

[47] Zhang, Z., and O. McNamara. (2018). Undergraduate Student Engagement: Theory and Practice in China and the UK. Singapore: Springer.

Zhe Zhang has served in the higher education sector for nearly 15 years. Before joining Harbin Institute of Technology (Shenzhen), he used to teach and conduct educational research at Shandong University (China), Leiden University (the Netherlands), The University of Manchester (UK) and Victoria University (Australia). He is interested in student engagement and development at university, particularly through the perspective of social and psychological theories. 